\title{
¿Para quién y para qué son buenas las buenas prácticas? Unión Europea, integración de (in) migrantes y despolitización/tecnificación de las politicas hegemónicas: un estudio de caso ${ }^{l}$
}

\author{
For whom and for what are best practices "best"? European \\ Union, migrant integration and the depoliticization/ \\ technification of hegemonic policies: a case study
}

\author{
Luca Sebastiani \\ Universidad de Granada \\ lucaseba78@ugr.es (ESPAÑA)
}

Recibido: 30.122015
Aceptado: 21.11 .2016

\section{RESUMEN}

Entre finales de los años noventa y comienzos del nuevo siglo se ha ido afirmando un marco político en el ámbito de la Unión Europea, el cual fomenta el alcance de un entendimiento común de la integración de inmigrantes y promueve la coordinación, financiación e intercambio de información y "buenas prácticas" entre los diferentes niveles institucionales afectados, a través de herramientas de "políticas blandas" (soft policy). En este artículo analizaré y discutiré algunas de las consecuencias más relevantes originadas del entendimiento del concepto de

${ }^{1}$ Este artículo constituye la re-elaboración y puesta en comunicación de dos anteriores ponencias: "Despolitizando y tecnificando: la construcción del 'objeto' integración en el marco de la UE", expuesta oralmente en el "Seminario de Investigación en Antropología Social y Diversidad Cultural", celebrado el 5 y 6 de marzo en el Departamento de Antropología Social de la Universidad de Granada y “¿Para qué y para quién son buenas las “buenas prácticas’?”, expuesta oralmente en el "Encuentro Internacional con Slavoj Žižek. Un intelectual para el siglo XXI", celebrado entre el 21 y el 25 de septiembre en el Centro Mediterráneo de la Universidad de Granada. En el texto articulo reflexiones a partir de los datos empíricos de mi tesis doctoral: "Análisis etnográfico de un dispositivo político transescalar: el marco de la Unión Europea para la integración de nacionales de terceros países", dirigida por Aurora Álvarez Veinguer y Francisco Javier García Castaño, defendida el 21 de julio de 2014 y financiada por el Plan Propio de Investigación de la Universidad de Granada (Programa 6A: Formación de Profesorado Universitario). 
"integración" por los principales actores implicados en este proceso, utilizando como ejemplo el caso de las "buenas prácticas" debido a su importancia dentro de los mecanismos de la "gobernanza multinivel" comunitaria. A través de este análisis, resaltaré que en el contexto comunitario, la noción de integración ha sido construida a través de un ejercicio de (aparente) despolitización y tecnificación, cuyos resultados sin embargo son contradictorios -puesto que el elemento político a menudo retorna y se manifiesta "en el trasfondo", "al margen" y "dentro" de lo técnico- a la vez que eficaces -en tanto en cuanto este ejercicio ha conseguido impulsar y moldear ciertas formas de saber, hablar y actuar sobre la integración de inmigrantes, naturalizando determinadas relaciones de poder existentes en la sociedad- . El material empírico para el presente artículo está basado en el trabajo de campo realizado en Bruselas entre 2011 y 2012 para la investigación doctoral. Consiste en entrevistas a los actores sociales y políticos más importantes del marco comunitario de la integración, en la observación de distintos encuentros y en la lectura de fuentes variadas.

\section{PALABRAS CLAVE}

Buenas prácticas; Unión Europea; integración de inmigrantes; políticas públicas; despolitización/tecnificación.

\section{ABSTRACT}

Between the end of 90s and the beginning of the new century, a political framework at European Union level has been established. This framework fosters the achievement of a common understanding of migrant integration and promotes mechanisms of coordination, funding, information exchange and "best practices" through the affected institutional levels, by means of soft law. In this paper I will analyse and discuss some of the most important consequences derived from the most important actors' understanding of "integration". I will use the case of "best practices" as an example, since they are considered as a fundamental tool within EU multi-level governance mechanisms. I will show that in the EU context, the very notion of integration has been constructed through an exercise of (apparent) depoliticization and technification, whose results are contradictory -since the political element often "returns" and manifests itself "at the bottom", "at the border" and "within" the technical element- and at the same time effective -since this exercise has been able to foster and shape certain ways of knowing, speaking and acting on migrant integration, naturalizing unequal power relations in society itself- . This paper is based on the empirical materials proceeding from the fieldwork done in Brussels between 2011 and 2012. It is made up of interviews done to the most important social and political actors within the EU integration framework, observations of various meetings and the reading of numerous sources. 


\section{KEY WORDS}

Best practices; European Union; migrant integration; policies; depoliticization/technification.

\section{INTRODUCCIÓN}

Si bien a diferentes velocidades, el concepto de integración se ha ido difundiendo en los últimos treinta años a lo largo y lo ancho del continente europeo, afirmándose como prisma interpretativo y eje articulador de las políticas públicas nacionales dirigidas a determinados sectores de la población (in)migrante ${ }^{2}$. En la última década, este paradigma se ha impuesto también al nivel de la Unión Europea (UE): sin embargo, conforme con el art. 79.4 del Tratado de Lisboa (2009), la UE no tiene la facultad de elaborar directivas sobre integración, pudiendo solo establecer medidas de apoyo a las políticas nacionales. A pesar, por tanto, de no existir "políticas de integración comunitarias" en sentido literal, entre finales de los años noventa y comienzos del nuevo siglo se ha ido afirmando un marco europeo que fomenta el alcance de un entendimiento común de la integración y promueve la coordinación, financiación e intercambio de "buenas prácticas" entre los diferentes niveles de gobierno a través de herramientas de "ley blanda" (soft law); esto es, mediante métodos de decisión informales y basados en la aproximación voluntaria de los actores implicados, en primer lugar los estados miembros.

En otros textos he argumentado que el entendimiento hegemónico ${ }^{3}$ de las políticas de integración en el contexto de la UE ha generado efectos tangibles y materiales, influyendo en las prácticas ${ }^{4}$ de los actores implicados en su elaboración, implementación y evaluación (véase Sebastiani 2014 y 2015). En cambio, aquí me centraré en otra cuestión, conceptualmente distinta aunque relacionada con la anterior: mostraré cómo, en este mismo marco comunitario, los contenidos asociados a la noción de integración han sido construidos a través de un ejercicio de (aparente) despolitización y tecnificación, cuyos resultados sin embargo son contradictorios, puesto que lo político retorna a menudo "en el trasfondo", "al margen" y "dentro de" lo técnico. En las siguientes páginas fundamentaré las razones que me llevan a esta conclusión, basándome en los

${ }^{2}$ El uso del paréntesis (que, después de la presente explicación, será abandonado para facilitar la lectura) se debe a un cuestionamiento del etnocentrismo implícito en la noción de inmigración, que al centrarse únicamente en el proceso de "llegada" a las sociedades receptoras simplifica y quiebra la unidad y complejidad de una experiencia que Sayad ha definido más apropiadamente como "emigración/inmigración" (2002).

${ }^{3}$ Aquí se utiliza la noción de hegemonía en una acepción gramsciana, en tanto "sentido común" de un determinado orden o época distinto del dominio o la coacción (véase Gramsci 2012).

Al hablar de "prácticas" de integración hago referencia a aquellas actividades orientadas a la "traducción" de objetivos políticos generales a medidas más específicas, y que se dan a través de varios instrumentos como leyes, declaraciones, dispositivos financieros, plataformas participativas, herramientas tecnológicas, etc. 
resultados del trabajo de campo realizado entre 2011 y 2012 para la escritura de mi tesis doctoral y seleccionando, de entre los materiales disponibles, el caso específico de las "buenas prácticas" que, al tener una importancia central dentro de las políticas blandas de integración comunitarias, serán tomadas como ejemplo paradigmático de una tendencia más general. Además, aunque otras investigaciones sobre las políticas contemporáneas de inmigración, integración y control fronterizo hayan subrayado ya la existencia de importantes elementos de despolitización en ellas (véanse Guiraudon 2003; Andrijasevic y Walters 2010; Bigo y Carrera 2007; Wacquant 2009; Mitsilegas 2012; De Genova 2016), no me consta que se hayan realizado estudios específicos sobre las buenas prácticas dentro del marco europeo de la integración. La estructura del trabajo es la siguiente: primero formularé un breve apartado teórico y otro metodológico, aclarando los procedimientos y conceptos adoptados para la producción y análisis de datos; a continuación aportaré un resumen de las medidas más importante impulsadas por la UE en el ámbito político de estudio, para posteriormente centrarme en las buenas prácticas para desmenuzar algunos aspectos del citado proceso de "despolitización/tecnificación"s. Finalmente, recapitularé los principales resultados y avanzaré una reflexión conclusiva.

Para terminar este apartado, cabe aclarar que el período en que se ha realizado el trabajo de campo remite a la anterior composición de la Comisión Europea, liderada por el portugués José Manuel Durão Barroso (en su segunda presidencia, entre 2009 y 2014) y siendo entonces Comisaria de Asuntos de Interior la sueca Cecilia Malmström. Al constituir las políticas públicas comunitarias un ámbito profundamente fluido y sujeto a constantes modificaciones, el intento del presente trabajo no es poner un "punto y final" sobre determinadas cuestiones ni abarcar el conjunto de las medidas comunitarias de integración producidas hasta la fecha, sino más bien formular análisis y consideraciones cuya utilidad posiblemente vaya más allá de su acotado contexto de nacimiento. Ni que decir tiene, estas consideraciones se verían enriquecidas por futuras aportaciones, marcadamente dirigidas a la más reciente actualidad y centradas en los procesos de construcción de significados puestos en práctica en el presente más inmediato de la arquitectura políticainstitucional comunitaria.

\section{MARCO TEÓRICO}

El concepto de integración tiene una trayectoria relativamente larga dentro de las ciencias sociales. Como bien observa Gil:

5 Aunque "despolitización” y "tecnificación" representen dos procesos distintos en términos conceptuales, al darse en este caso de manera paralela y especular serán abordados como un conjunto: de ahí que algunas veces hable de "despolitización/tecnificación". 
En el campo sociológico, es difícil hablar de integración sin pensar en Durkheim, su atención al lazo social y su diferenciación entre solidaridad orgánica y solidaridad mecánica con relación al proceso de división internacional de trabajo. La noción de integración y sus sinónimos (inclusión, incorporación, acomodación) nombran esencialmente toda clase de mecanismos y estructuras dirigidas a reproducir una solidaridad unificada que supere las fracturas (clase, género, origen) que amenazan el orden social y nacional (Gil, 2006: 398).

En su traslación al campo de las políticas públicas, el concepto no estaba inicialmente asociado a las migraciones, estando más bien vinculado a un conjunto de intervenciones más amplias encaminadas a generar cohesión social: es solamente a partir de los años setenta del siglo pasado cuando empieza a establecerse una relación directa. Esta transformación remite a dos acontecimientos: por un lado, la presencia de "trabajadores invitados" extranjeros en los países mayormente industrializados de Europa septentrional y occidental se convierte en permanente, y por el otro, las incipientes políticas neoliberales contribuyen a impulsar una "metamorfosis de la cuestión social" (Castel 1997), en donde las afiliaciones identitarias previas -concebidas principalmente en términos de clase- comienzan a deshacerse, para poner en el centro la cuestión de la "diferencia cultural" (véanse Favell 2001a y 2001b; Joppke y Morawska 2003; Gil 2011).

Para los fines de este trabajo interesa resaltar que la emergencia del concepto de integración, en tanto que objeto de estudio y eje articulador de formas y contenidos específicos de intervención pública dirigidos a la población inmigrante, lejos de poderse asumir de manera naturalizada ha de entenderse como consecuencia de una construcción social. Lo que esta noción pueda significar en un momento dado, antes que representar una mejor o peor aproximación a una situación "realmente existente", "objetiva" y "palpable", es la cristalización provisional del resultado -histórico y, por tanto, siempre inacabado- de una "lucha por el sentido", protagonizada por los principales actores presentes en su "campo político" (Bourdieu y Wacquant 2005) de definición ${ }^{6}$.

Por ende, el marco teórico utilizado asume la naturaleza performativa de las políticas públicas: estas, lejos de formular una simple descripción de lo existente, tienden a (re)producirlo de una manera peculiar, le proporcionan sentidos específicos, y a través de sus "problematizaciones" (Foucault 2009) abren o cierran ciertos horizontes de posibilidad para el pensamiento y la acción.

${ }^{6}$ Por tanto, aun asumiendo como punto de partida analítico la acepción actualmente vigente de integración y de las relativas políticas, siempre tendré en cuenta que esta no deja de estar caracterizada por ambigüedades, al ser el objeto de distintas resignificaciones operadas por actores socio-políticos situados (en función de sus intereses, habitus, marcos cognitivos, etc.). Por ejemplo, en otros textos he observado la existencia de una "alianza discursiva" entre la Comisión Europea y algunas importantes ONG, actores que se consideran defensores de una noción "proactiva" de integración opuesta a la visión "restrictiva" de otros estados nación (véase Arribas et al. 2014). 
Tal y como afirman Shore y Wright: "Las políticas públicas se expresan a través de secuencias de eventos; crean nuevos espacios sociales y semánticos, nuevos conjuntos de relaciones, nuevos sujetos políticos y nuevas redes de significados" (2011: 1); a veces, incluso "asumen una vida propia con consecuencias que van más allá de las intenciones originales" (2011: 3). En cierto sentido, pueden ser interpretadas como "textos culturales" (Shore y Wright 1997), pues están influidas por las historias y los supuestos socio-culturales de quienes las elaboran. Esto a pesar de ser a menudo confeccionadas y presentadas a través de un lenguaje pretendidamente "racional" y "científico", o mediante descripciones supuestamente "neutrales" de los "problemas realmente existentes".

Entonces, asumiendo el punto de vista de estos autores se vuelve imprescindible estudiar los discursos sobre la integración no tanto en relación a un objeto supuestamente pre-existente (la "integración" y los conceptos asociados a ella), sino a partir de sus propias condiciones históricas, sociales y culturales de producción. En este sentido, Balbi y Boivin consideran que la ventaja de un enfoque de este tipo (por ellos llamado "etnográfico") radica en su capacidad para evitar el error de "congelar" nociones (en su caso las de "política", "estado" o "gobierno", pero bien podría hablarse de "integración" o "inmigrantes") a menudo asumidas como unívocas desde quienes elaboran las políticas públicas:

En lugar de intentar vanamente atribuir a cada uno de esos términos un sentido preciso, unívoco e inequívoco, el análisis etnográfico permite dotarlos de múltiples sentidos que, además, no resultan de la especulación teóriconormativa de quien escribe sino del examen detallado de sus usos por parte de actores socialmente situados (Balbi y Boivin 2008: 10).

Otras ventajas derivadas de este acercamiento son su aptitud para poner de relieve la naturaleza profundamente instrumental de las políticas públicas, así como su vocación "mítica": en efecto, en su constante necesidad de imponer "orden" y "coherencia" a un mundo necesariamente imperfecto, terminan produciendo "narrativas retóricas que sirven para justificar -o condenar- el presente, y algo más usual, para legitimar a quienes están en posiciones de autoridad establecidas" (Shore 2010: 32).

\section{PROCEDIMIENTO METODOLÓGICO}

En este apartado resumiré la metodología utilizada para la realización de la tesis doctoral, en cuyos materiales se han fundamentado las argumentaciones para el presente artículo. Se ha tratado básicamente de un acercamiento cualitativo, consistiendo en 35 entrevistas abiertas semidirigidas ${ }^{7}$, hechas entre

${ }^{7}$ Para mantener el anonimato de los interlocutores citados, he modificado de manera aleatoria su género y alterado ligeramente la fecha de la entrevista. Igualmente, todas las traducciones de 
febrero de 2011 y junio de 2012, a distintos actores implicados en el marco de las políticas blandas de integración de la UE (casi todas realizadas en Bruselas). Más específicamente se han entrevistado:

- 10 portavoces de ONG "paraguas" europeas (estructuradas como federaciones de organizaciones nacionales) y 4 de ONG estatales;

- 10 miembros de instituciones comunitarias (funcionarios de la Comisión Europea -Dirección General de Asuntos Interiores y Dirección General de Justicia-, del Comité Económico y Social, del Comité de las Regiones, de la Secretaría General del Consejo de la UE, asesores de grupos parlamentarios) y 2 de instituciones estatales (representantes ante la UE para las políticas de integración);

- 3 exponentes de think tank europeos ("expertos", analistas políticos, autores de estudios a menudo comisionados por las instituciones comunitarias);

- 2 representantes de redes europeas de administraciones regionales y locales;

- 1 responsable de una federación europea de organizaciones empresariales y otro de una federación de sindicatos;

- 1 portavoz de una fundación europea dedicada a asuntos de integración;

- 1 funcionario de una organización internacional sobre migraciones.

Igualmente, se han realizado observaciones de conferencias, debates, encuentros políticos e institucionales sobre la integración en los que hayan participado actores relevantes para el estudio (celebrados principalmente en Bruselas pero también en otros lugares), como por ejemplo:

- Sesiones del "Foro Europeo sobre la Integración" celebradas en los locales del Comité Económico y Social Europeo;

- Sesiones de la Comisión LIBE (Libertades Civiles, Justicia y Asuntos de Interior) del Parlamento Europeo;

- Conferencias y debates realizados en sedes universitarias o en espacios institucionales comunitarios -como la sede de delegaciones regionales ante la UE-;

- Los distintos lugares de las entrevistas, hechas en la mayoría de los casos en el puesto de trabajo de los interlocutores.

Finalmente, los textos utilizados como fuentes primarias han sido principalmente: comunicaciones y documentos de trabajo de la Comisión Europea, declaraciones de sesiones del Consejo Europeo y decisiones del Consejo de la UE, dictámenes del Comité Económico y Social y del Comité de las Regiones, declaraciones del Parlamento Europeo y de la Presidencia de turno de la UE, registros de los grupos de presión, notas de prensa, reglamentos, convocatorias y resoluciones de proyectos europeos, actas de conferencias, encuentros y consultas públicas, informes, folletos, fascículos, artículos de periódicos y portales web.

En lo que respecta al procedimiento de análisis, los materiales

otro idioma, ya se trate de citas de textos o fragmentos de entrevistas, son propias. 
(transcripciones de entrevistas, notas de campo, fragmentos de textos) han sido procesados mediante el software QSR NVivo (versión 10), dando lugar a unas 60 categorías de análisis "abiertas" (incluyendo también sub-categorías). Dentro de este corpus, la selección de los datos relevantes se ha llevado a cabo adoptando un criterio de relevancia cualitativa-estructural (poniendo en el centro la representatividad de los significados). En particular, se han tenido en consideración todos los materiales que hicieran una referencia explícita al concepto de buenas prácticas.

\section{UN RÁPIDO BOSQUEJO DEL MARCO EUROPEO}

En este apartado no realizaré una descripción exhaustiva de las medidas implementadas a nivel comunitario en materia de integración, sino más bien propondré un breve esquema cronológico sobre las principales herramientas establecidas durante los últimos años, hasta la fecha de realización del trabajo de campo ${ }^{8}$. Al hacerlo, y basando mis observaciones en los materiales de campo anteriormente mencionados, trataré de ilustrar tres movimientos generales a los que ha sido sometida la noción de integración en su proceso de construcción, fundamentales para que se desencadenara la mencionada dinámica de despolitización y tecnificación: en primer lugar esta ha sido transformada en un "objeto político", es decir, convertida en una problemática "realmente existente" y a gestionar mediante políticas públicas adecuadas e intervenciones específicas. En segundo lugar, se han visibilizado los diferentes elementos por los que la integración estaría compuesta: estos han sido desglosados, recopilados y comparados en multitud de documentos e informes. En tercer lugar, la noción ha sido operacionalizada mediante el establecimiento de principios, recomendaciones, objetivos concretos a cumplir, así como instrumentos para "medir" y evaluar su mayor o menor logro.

Cabe así empezar recordando que en las Conclusiones del Consejo Europeo de Tampere (1999) se encuentra por primera vez el llamamiento al "trato justo de los nacionales de terceros países" y a "una política de integración más decidida" (Consejo Europeo 1999). Al cabo de tan solo un año estas declaraciones se traducirán en la aprobación de dos directivas, sobre la "Igualdad Racial" (2000/43/EC) y la "Igualdad en el Empleo" (2000/78/EC). Sin embargo, la perspectiva originaria de anti-discriminación será rápidamente reemplazada por un enfoque "de ministerio de interior", vinculando estrechamente integración

${ }^{8}$ Además, cabe subrayar que algunas de esas herramientas, posteriormente a la realización de la investigación han sido sustituidas por otras medidas. Por otra parte, en el momento del trabajo de campo el discurso hegemónico comunitario no estaba aún tan pesadamente influido como ahora por los acontecimientos ligados a la actual "crisis de los refugiados". De todas formas, aquí no importa reseñar detalladamente el conjunto de las transformaciones acontecidas hasta la actualidad, sino más bien esbozar el contexto normativo en el que se realizó la investigación, para entender mejor el funcionamiento de las dinámicas de despolitización/tecnificación que constituyen el objeto de estudio del texto. 
y políticas migratorias (Guiraudon 2003). A partir de este momento es posible observar la dinámica descrita arriba, que se manifiesta a lo largo de acontecimientos como los siguientes:

- El establecimiento en 2002 de la red de los Puntos de Contacto Nacionales sobre Integración (PCNI), representantes estatales encargados de reunirse con la Comisión Europea para implantar una "cooperación técnica" y "fijar unos objetivos comunes" (Comisión Europea 2010: 17);

- La adopción por el Consejo Europeo de Justicia y Asuntos de Interior (JAI) de once Principios Básicos Comunes (PBC), que definen la integración como un "proceso bidireccional y dinámico de ajuste mutuo por parte de todos los inmigrantes y residentes de los Estados miembros" y desglosan sus principales componentes: el respeto a los "valores de la UE"; el conocimiento del idioma y las costumbres de la "sociedad de acogida"; el acceso al empleo, la educación y los servicios sociales; el diálogo intercultural e interreligioso; la participación social y política y el desarrollo de "objetivos, indicadores y mecanismos de evaluación" de las políticas públicas que permitan valorar el mayor o menor alcance de las metas establecidas (Consejo de la Unión Europea 2004) ${ }^{10}$;

- La publicación (entre 2004 y 2007) por parte de la Comisión de tres Informes Anuales sobre Migración e Integración, los cuales procuran visibilizar la problemática recién creada mediante la recopilación de informaciones sobre las políticas y las estadísticas de la integración procedentes de diferentes países y proporcionadas por los $\mathrm{PCNI}^{11}$;

- La edición por la Comisión Europea y el think tank "Migration Policy Group" (MPG) de tres diferentes versiones del "Manual sobre la integración para responsables de la formulación de políticas y profesionales" (2004, 2007, 2010), elaboradas a través de 14 seminarios técnicos y con la participación de alrededor de 100 personas entre los PCNI y las delegaciones nacionales nombradas por estos últimos (básicamente: expertos, académicos, administradores y ONG). Al contener informaciones y recomendaciones sobre las buenas prácticas, los Manuales operacionalizan las políticas de integración a fin de fomentar el "aprendizaje mutuo". Son concebidos como "un proceso continuo e integrador", que aporte conocimiento sobre "iniciativas nuevas, soluciones y resultados de las

9 Cabe puntualizar que por inmigrantes la UE entiende "nacionales de terceros países", puesto que los desplazamientos de los ciudadanos comunitarios por razones de vida o de trabajo ni siquiera son definidos "migración", sino "movilidad interna". Además, a pesar de la aparente amplitud de la expresión "todos los inmigrantes", en los instrumentos concretamente predispuestos -a partir de los financieros- se hace referencia expresamente a las personas que estén en condiciones de residencia "legal".

${ }^{10}$ Los PBC serán retomados y confirmados por la Comunicación de la Comisión Europea "Programa Común para la Integración” COM(2005)389 final, que tratará de traducirlos en orientaciones concretas.

${ }_{11}$ Otros eventos que darán lugar a esta visibilización serán las Conferencias Ministeriales sobre la Integración de Groningen (2004), Potsdam (2007), Vichy (2008) y Zaragoza (2010). 
evaluaciones realizadas" (Comisión Europea 2010: 22) ${ }^{12}$;

- El Fondo Europeo para la Integración, establecido en 2007 como continuación del anterior programa INTI ("Acciones preparatorias para la integración de los nacionales de terceros países") y destinado a apoyar proyectos nacionales y transnacionales para la implementación de los PBC (por un total de 825 millones de euros para el período 2007-2013). El Fondo establece complejos mecanismos de reparto y asignación de las subvenciones cuyo objetivo, en última instancia, es alentar el impulso de proyectos que sean coherentes con la noción comunitaria de integración (véase Sebastiani 2015) ${ }^{13}$;

- El Foro Europeo sobre la Integración (2009), una plataforma de diálogo entre la Comisión Europea, el Comité Económico y Social y otros exponentes de la "sociedad civil" (en larga medida organizaciones gubernamentales de nivel europeo y estatal) ${ }^{14}$. Como he argumentado en otros artículos, las pautas participativas muy formalizadas del Foro tienden a "encauzar" la agencia de sus actores y generan nociones y saberes alineados con las definiciones hegemónicas de la UE (Sebastiani 2014);

- La Web Europea de la Integración (2009), una plataforma virtual que fomenta la proximidad y la interacción entre los principales actores en este ámbito;

- Los debates sobre los "indicadores" y los "módulos", impulsados particularmente después de la cumbre de Zaragoza (2010). El primero alude a la búsqueda de un procedimiento compartido para armonizar y comparar los datos estatales sobre la integración, facilitando así la evaluación del estado de las políticas. Los módulos, en cambio, constituían una suerte de profundización en el desarrollo, la operacionalización y la estandarización de los contenidos de los Manuales ${ }^{15}$;

- La Comunicación de la Comisión "Agenda Europea para la Integración de Nacionales de Terceros Países" COM(2011) 455 final, que hace un balance de lo realizado hasta entonces y plantea la necesidad de enfoques novedosos, abogando por la "integración mediante la participación", "más medidas a nivel

${ }^{12}$ En 2010 el Migration Policy Group publicará "From principles to practice" (2010), un escueto documento que aspira a demostrar la estrecha relación existente entre cada uno de los Principios Básicos Comunes y las diferentes recomendaciones contenidas en los Manuales. En las 101 Conclusiones se recopilan además las "lecciones aprendidas" desde las prácticas (Migration Policy Group 2010: 7).

${ }_{13}$ El Fondo Europeo para la Integración ha sido objeto de revisión debido a las muchas críticas recibidas, en particular por su mecanismo de funcionamiento considerado demasiado rígido y de "compartimentos estancos". Posteriormente ha sido sustituido por el "Fondo Europeo de Migración y Asilo", caracterizado por mecanismos de funcionamiento diferentes.

${ }_{14}$ Posteriormente sustituido por el "Foro Europeo sobre la Migración".

15 Sin embargo, en las fechas de realización del trabajo de campo ambos debates se encontraban atascados. En el primer caso, principalmente por las resistencias de los estados miembros a ser "juzgados" por la Comisión Europea a través de los indicadores. En el segundo porque, según me han comentado muchos interlocutores, a pesar de que en los diferentes seminarios técnicos todo el mundo pareciera estar de acuerdo en la necesidad de los módulos, pocos tenían claro cómo estos se concretarían en la práctica. 
local" y la "implicación de los países de origen". Esta última prioridad resulta de particular interés, porque al afirmar la hipótesis de que la integración empieza desde el exterior mediante medidas previas a la salida, la redefine como un proceso ya no simplemente "bidireccional", sino "tridireccional" entre la persona migrante, la sociedad receptora y la de origen.

No es casualidad que esta más reciente insistencia en la "dimensión exterior de la integración" vaya de la mano de las prioridades comunitarias en el ámbito de políticas migratorias, centradas en la "cooperación" con los países de origen en materia de retorno y el fomento de la migración circular ${ }^{16}$ : lo cual pone de relieve la discordancia existente entre el esfuerzo por desarrollar un discurso "científico" sobre la integración y los determinantes políticos que intervienen en las transformaciones del concepto mismo.

\section{UN CASO DE ESTUDIO CONCRETO: LAS "BUENAS PRÁCTICAS"}

En el apartado anterior he ilustrado desde una perspectiva diacrónica la construcción del "objeto político" integración, así como la creciente "visibilización" y "operacionalización" de sus componentes. En el presente, primero fundamentaré la relevancia de las "buenas prácticas" dentro de este proceso general; a continuación me detendré en analizar cómo esta noción vertebra una lógica (aparentemente) despolitizadora y tecnificadora y finalmente presentaré el movimiento de "retorno" de lo político en sus diferentes acepciones.

\subsection{Las razones de esta elección}

A fin de mostrar la importancia paradigmática de las buenas prácticas dentro del proceso de tecnificación/despolitización y justificar su elección como ejemplo, las contextualizaré dentro de la "forma de hablar" sobre la integración hegemónica en el marco de la UE.

Para empezar, esta es presentada como un objetivo necesario, indiscutible, evidente; un proceso a realizarse, una exigencia "racional". La idea subyacente es que la diversidad -entendida casi exclusivamente como consecuencia de los procesos migratorios- constituye a la vez un desafío y una oportunidad de enriquecimiento económico y "cultural". Por consiguiente, tiene que ser "gestionada" en aras de "activar" una integración "exitosa". En las palabras de la entonces Presidencia sueca de la UE:

16 Véanse por ej. las teorizaciones sobre el "Enfoque Global" COM(2011) 743 final. Parece así configurarse una suerte de "externalización" de las mismísimas políticas de integración, después de las de control migratorio y de asilo. 
La migración crea diversidad, la diversidad crea libertad y una dinámica social y económica [...]. Pero la migración también plantea retos. La migración sin una política de integración efectiva no solo es dañina para la economía estatal, sino que también es un desperdicio de potencialidades humanas (Bildt 2009).

Es importante insistir en que los actores comunitarios reiteran incesantemente el imperativo de actuar mediante políticas públicas para no dejar las migraciones "a sí mismas". A este respecto, una entrevistada particularmente crítica ha caracterizado el enfoque de la UE de la siguiente manera:

La manera en la que hablan de ella [la integración], tan segura, pero en realidad sin saber, probablemente sin haber hablado nunca siquiera a un migrante que haya tenido problemas [...]. Sin embargo es siempre: "Integración, integración, tenemos que hacer esto, tenemos que hacer eso", sin tener en cuenta verdaderamente los diferentes aspectos (entrevista a la portavoz de una ONG, 16/3/2011).

Por supuesto, esta proclamada necesidad de intervenir y de hacerlo a través de políticas de integración, por muy naturalizada que esté, no deja de constituir una problematización específica y nada neutral de la cuestión. Ahora bien, la prioridad otorgada a la dimensión interventora no justifica cualquier tipo de actuación. Ante un tema tan "sensible" como es la presencia migratoria, vivido por muchos ciudadanos con una fuerte sobrecarga "irracional" y emotiva y a menudo instrumentalizado por los "populismos", se vuelve prioritario un enfoque no sensacionalista, "basado en la evidencia" (Comisión Europea 2010: 51) y "fiel a la realidad" (Comisión Europea 2010: 59) ${ }^{17}$. A lo largo de mis observaciones he sido testigo de repetidos llamamientos a hablar de la integración de una manera "equilibrada", "fundamentada en hechos" y "no ideológica", al igual que he podido refrendar la permanencia de este patrón en varias entrevistas -especialmente en aquellas realizadas a representantes institucionales-, donde las invitaciones a no vivir en el mundo de las "bonitas ideas" y a ser "realistas" han sido un tópico recurrente ${ }^{18}$.

Es por tanto en los anteriores planteamientos que radica la importancia de las buenas prácticas. Esta noción al sugerir un enfoque "pragmático", basado

${ }^{17}$ Es curioso que justo algunas líneas después de plantear semejante enfoque se hable de "oleadas de inmigrantes" (Comisión Europea 2010: 60), utilizando una "metáfora acuosa" (Santamaría 2002) que lejos de ser objetiva reproduce la idea de un "flujo" de personas imparable y amenazante.

18 Sin embargo, ¿este llamamiento al realismo no es también ideológico? Toda ideología, para llegar a ser hegemónica, necesita ocupar el espacio de la universalidad con sus propios conceptos particulares, presentándolos como "apolíticos" y descalificando los puntos de vista concurrentes, que son definidos "ideológicos", "politizados" o "partidarios" (Žižek 2010: 15). De esta manera se establece un orden de lo posible, que funcionando como un tamiz margina las alternativas existentes, separando lo "viable" de lo "infactible", lo "realista" de lo "utópico". Para un debate sobre la noción de ideología véase Žižek (2003). 
en la experiencia y no politizado, ha jugado un papel fundamental a la hora de permitir ese "halo" de consenso necesario para aglutinar a una pluralidad de actores, diversamente posicionados, en torno a un marco común de la integración.

\subsection{Primer movimiento: reducción a una cuestión técnica}

Para analizar más detenidamente el funcionamiento de esta noción, empezaré por la definición oficial de "buenas" o "mejores" prácticas: "Fórmulas que han demostrado, por medio de la investigación y la evaluación, su eficacia y sostenibilidad, que producen resultados sobresalientes y que pueden ser aplicables y adaptables a otras situaciones" (Comisión Europea 2004: 13).

Cabe resaltar que la concepción de la realidad social emergente de estas líneas tiene fuerte tintes cientifistas. En efecto, se habla en un sentido algo positivista de fórmulas, las cuales a través de mecanismos de evaluación apropiados serían capaces de demostrar su propia eficacia y que, además, según un paradigma cuasi-experimental podrían extraerse de contextos socio-culturales específicos y trasplantar en otros. Este concepto de buenas prácticas fomenta así una comprensión "diagnóstica" de la integración, entendida como un proceso que puede activarse adoptando las "recetas" adecuadas, es decir, aquellas "que funcionan"19. Desde este punto de vista, las tres ediciones del arriba citado "Manual sobre la integración para responsables de la formulación de políticas y profesionales" pueden concebirse como un compendio relativo al "cómo funciona" y el "cómo se hace" de la integración. Tal y como me comentó un interlocutor perteneciente al mundo de los think tank bruselenses:

Creo que ahora los PBC han sido operacionalizados mucho mejor, ahora ayudan a entender cómo funciona todo, cómo crear un cuerpo consultivo, cómo integrar las políticas de integración en una perspectiva de conjunto, cómo trabajar de manera simultánea en el empleo y la educación [...] Creo que si miras esas publicaciones puedes ver que la cooperación técnica ha avanzado en el establecimiento de los "factores de buenas prácticas", ¿sabes? ¿Cómo se hace esto? Así pues, creo que si eres un profesional puedes coger el Manual y aclararte sobre los pasos a dar, así como tener algunas buenas ideas (entrevista a un think tank, 29/3/2011).

19 De manera análoga, los promotores del New Labour inglés de Tony Blair solían "subrayar la pertinencia de prescindir de los prejuicios y aplicar las buenas ideas, vengan de donde vengan (ideológicamente). Pero, ¿cuáles son esas ‘buenas ideas’? La respuesta es obvia: las que funcionan. Estamos ante el foso que separa el verdadero acto político de la 'gestión de las cuestiones sociales dentro del marco de las actuales relaciones sociopolíticas': el verdadero acto político (la intervención) no es simplemente cualquier cosa que funcione en el contexto de las relaciones existentes, sino precisamente aquello que modifica el contexto que determina el funcionamiento de las cosas" (Zižek 2010: 34). Para otra crítica a la idea de políticas "que funcionan", véase Hammersley (2013). 
Cabe añadir que esta definición tecnicista radica en un supuesto epistemológico "oculto": se trata del postulado según el cual sería posible aprehender la realidad social "tal y como es" más allá de cualquier posicionamiento previo. La idea de fondo es que los "huecos" de conocimiento se pueden llenar generando más información a lo largo de un proceso acumulativo, el cual desembocaría en una creciente eficacia de las políticas públicas (Shore y Wright 1997). De esta manera se erradica todo tipo de reflexión sobre la naturaleza situada del conocimiento (Haraway 1988), operando una separación artificial entre lo "técnico" y lo "político" y obviando que todo saber está imbricado en relaciones de poder (Foucault 2009). Si se actúa mal es básicamente por falta de conocimiento y, por ende, una actuación será tanto más eficaz cuanto más esté informada por el conocimiento "objetivo" de una determinada realidad. Resulta llamativa la afirmación de un administrador regional, quien preguntado sobre los temas de debate con sus homólogos durante los encuentros europeos de intercambio de buenas prácticas quiso aclarar que las cuestiones discutidas no eran políticas sino meramente técnicas, pues el único objetivo perseguido era el intercambio de buenas prácticas (entrevista a un administrador regional, 11/3/2011). Es tal vez gracias a este entendimiento tecnicista de la integración, que se ha podido generar una cantidad impresionante de instrumentos y medidas de manera tan rápida, en tan pocos años (entrevista con un think tank, 6/6/2012).

Finalmente -como han resaltado varios entrevistados- es interesante notar que no existen definiciones de las "malas" o "peores prácticas": en el corpus comunitario de la integración no se encuentran referencias explícitas a lo que no se debe hacer, ni tampoco a malos ejemplos encarnados por algún actor concreto. Cabe preguntarse si su falta es, al menos parcialmente, una condición/ consecuencia del proceso más amplio de neutralización de la dimensión política de la integración, que trae aparejada la exigencia de eliminar los aspectos potencialmente más "críticos" o fuentes de posibles crispaciones. Si para relevantes teóricos contemporáneos, una característica consustancial a toda realidad política es su dimensión de "desacuerdo" (Rancière 1996), así como su naturaleza antagónica o adversarial (Mouffe 2007), esta operación de signo inverso pretende exactamente eliminar la visibilización de la naturaleza conflictiva de las políticas públicas comunitarias incluso dentro de un ámbito hegemónico, en el cual no cabe esperarse "rupturas sistémicas" o dinámicas contenciosas. Así pues, a manera de ejemplo, en los Manuales sobre la Integración de la Unión Europea la palabra "politización" es mencionada solo dos veces y siempre asociada a un contenido negativo, a una idea "irracional" y "emocional" de conflicto social que parece poner en tela de juicio el objetivo prioritario de la "cohesión social". La dimensión "pospolítica" (Rancière 1996), por tanto, parece ser un cimiento fundamental para el repertorio discursivo de las buenas prácticas, tal como emerge en la observación realizada por otra exponente de la sociedad civil europea: 
A ciertas alturas del consenso ya no hay política. Es consenso sin más, y por eso es tan difícil entenderlo, puesto que a menudo parece algo tan vacío, que ya uno no se da cuenta de qué contenidos estamos hablando. Pon el caso de los módulos: es algo que no se entiende, dado que allí en realidad no hay política, solo se habla de buenas prácticas, ¿pero qué es una buena práctica? Tú que eres antropólogo sabes que es absurdo pensar poder difundir una muy buena práctica de un contexto cultural e histórico a otro con un trasfondo totalmente distinto" (entrevista con representante de una ONG europea, 25/3/2011).

\subsection{Segundo movimiento: a veces (los contenidos políticos) retornan}

Las buenas prácticas también constituyen un caso paradigmático a la hora de evidenciar las contradicciones subyacentes en la operación despolitizadora y tecnificadora; así pues, en este epígrafe seguiré utilizando el ejemplo para ilustrar la existencia de un movimiento opuesto: un "coletazo", una suerte de "retorno" de lo político en sus diferentes vertientes -en el trasfondo, al margen y dentro de lo técnico-.

1) A lo largo de las entrevistas -especialmente las realizadas a funcionarios de la Comisión, a algunos "expertos" y a las ONG europeas más relevantes- he podido constatar que el uso de un lenguaje más "frío", "racional" y "científico" responde al menos parcialmente a una estrategia política consciente. El objetivo de esta operación parece ser el de salirse del terreno fuertemente "emocional" y "sensacionalista" que caracterizaría el actual escenario político-social, bien ejemplificado por el refrán recurrente en el entorno comunitario: "no son buenos tiempos para la integración". En este sentido, el desarrollo de un enfoque "basado en las evidencias" serviría para contrastar los "populismos" "oportunismos electoralistas" y para limitar los márgenes de maniobra de ciertos gobiernos nacionales reacios a extender las competencias comunitarias en el ámbito de la integración. Para decirlo en las palabras de un protagonista:

Los cambios en las políticas de integración a menudo no están basados en hechos comprobables [...]; en muchos ámbitos están siendo crecientemente guiados por las percepciones públicas, así pues no tienen que ver con cómo la integración está funcionando en el terreno, sino con las seguridades o inseguridades públicas, o con los cambios como consecuencia de elecciones... (entrevista a un think tank, 29/3/2011).

${ }^{20}$ Si bien es verdad que, durante los tiempos de mi trabajo de campo, los fautores de la estrategia despolitizadora ubicaban sus preocupaciones en el auge de los movimientos racistas y de extrema derecha, nada impide que este mismo mecanismo sea utilizado a modo de escudo ante otras opciones muy distintas de carácter "progresista". Sin ir más lejos -y situándonos por un momento fuera de las políticas de integración-, las acusaciones de populismo llevadas a cabo, por parte de sectores políticos estrechamente relacionados con las élites económicas y financieras de la UE, contra formaciones como Syriza primero y luego Podemos, indica que este repertorio discursivo "realista" y "tecnicista" se presta a usos diversos. 
Otra posible razón para reducir instrumentalmente a "técnicos" asuntos políticos, puede ser la de querer imponer más fácilmente decisiones ya tomadas por los actores más "poderosos", dado que su sustracción de la arena pública dificulta que puedan ser objeto de críticas. Tal como observa la portavoz de una ONG hablando de un intento de negociación fallido:

Básicamente nos dicen que es todo una cuestión técnica, y que solo cabe estar de acuerdo [...] Ni siquiera explicaron de qué iba la cuestión, solamente dijeron: 'Es demasiado técnico, no hay manera de oponerse, solo toca aceptarlo'. Aun así tratamos de desafiarlos, de pedir que se explicaran, y que ya decidiríamos si aceptar o no, pero ellos ni siquiera tenían la intención de negociar (entrevista con representante de una ONG europea, 18/6/2012).

Así pues, es pertinente hablar del retorno de lo político en un primer sentido, aludiendo al hecho de que la despolitización y tecnificación de la integración responden en realidad a una estrategia política más o menos implícita y latente en el trasfondo del debate técnico.

2) Ante una definición formal algo "hueca" y "escueta" -o quizás gracias precisamente a ella-, es posible observar una gran variedad empírica de "buenas prácticas". A modo de ejemplo, se incluyen: programas de formación laboral y de reconocimiento de las cualificaciones previas; creación de plataformas de diálogo intercultural; desarrollo de indicadores de varios tipos; medidas dirigidas a barrios con "alta concentración de inmigrantes"; planes de antidiscriminación; cursos de formación para líderes religiosos; proyectos de sensibilización para la población; intervenciones en el ámbito educativo; cursos de introducción para los "recién llegados"... (Comisión Europea 2004, 2007 y 2010). No puede olvidarse que desde el comienzo del intercambio de experiencias, los PCNI, expresión de los estados, han sido los principales encargados de recopilar y divulgar las buenas prácticas. Así pues, no extraña que en la última década se haya abierto un "campo de batalla" al nivel de la UE, en el que los gobiernos al mando en los diferentes países han estado articulando alianzas con sus semejantes más afines en aras de reivindicar sus propias prácticas como las "mejores", ganar más influencia política ante la Comisión Europea y, no por último, tener acceso a los canales de financiación comunitaria ${ }^{21}$. Por poner un ejemplo, dentro de la red de los PCNI, Países Bajos y Dinamarca estuvieron apoyándose recíprocamente, patrocinando como "buenas prácticas" unas medidas de integración en materia de reagrupación familiar consideradas restrictivas en muchos ambientes (entrevista al portavoz

${ }^{21}$ A partir de su establecimiento, el Fondo Europeo para la Integración ha venido asumiendo una creciente importancia, tanto porque en algunos países "nuevos miembros" de la UE ha constituido la única partida presupuestaria sobre integración, como porque en otros países "antiguos miembros" ha sido utilizado para compensar los recortes practicados en gastos sociales (Carrera y Atger 2011). 
de una ONG, 11/3/2011). De igual manera, algunos gobiernos han aprovechado la ambivalencia de los Principios Básicos Comunes para legitimar una medida tan cuestionada como el "test cívico" y presentarla como una implementación del marco común europeo ${ }^{22}$.

Por consiguiente, emerge un segundo sentido en el que cabe hablar de retorno de lo político: poniendo de relieve que, al margen de lo técnico, hay una disputa entre actores situados por la definición, la legitimación y la difusión de las mejores prácticas.

3) Es menester resaltar que el afán despolitizador/tecnificador ha envuelto algunas cuestiones, tan difícilmente reducibles a una cuestión puramente "científica", como es el tema de la lengua. Hágase caso a la manera "tecnicista" en la que un experto entrevistado presenta el proceso de aprendizaje de la lengua del país receptor por parte de la persona migrante:

Bueno, ¿qué ministerio tiene la competencia del aprendizaje de la lengua? En realidad es el Ministerio de Educación, no el de Interior. ¿Qué estándares hay para enseñar el italiano como segundo idioma? ¿Cuál es el marco europeo común de referencia para la lengua? ¿Y si nos dijeran cómo deberíamos organizar nuestros cursos de lengua? Si se comienza a perseguir estos objetivos, tal y como los módulos querían hacer, habrá que implicarse en un proceso de fijación de estándares, que es mucho más técnico (entrevista con un think tank, 29/3/2011).

No es mi intención minusvalorar la relevancia del idioma del país receptor, ni tampoco negar la existencia de elementos técnicos relacionados con su aprendizaje. Sin embargo quiero dirigir la atención hacia una cuestión previa que no suele ser problematizada en el discurso comunitario: la lengua nacional, por mucho que sea despolitizada y tecnificada, no deja de mantener una carga política relevantísima, estando vinculada a procesos de construcción simbólica e identitaria y también a componentes emocionales ${ }^{23}$. No de casualidad, un módulo entero de los tres propuestos por la Comisión Europea hasta la fecha de la investigación, se dedicaba a los cursos de "acogida" y a las clases de lengua, tratándose además del que más aprobación había logrado entre los estados miembros. Tampoco es irrelevante que el gobierno de una

22 Algunos observadores han subrayado que en particular los PBC n. 2 y n. 4, al hablar de "respeto a los valores básicos de la UE" y "conocimiento básico del idioma, la historia y las instituciones de la sociedad de acogida" podrían entrar en contradicción con la definición de la integración como proceso bidireccional proporcionada por el PBC n. 1 (Carrera y Atger 2011). Aparte de manifestar una visión etnocéntrica, estos principios han sido utilizados por muchos gobiernos a la hora de justificar la implementación de los mencionados test "cívicos", poniendo el conocimiento del idioma como condición obligatoria y vinculante a la hora de poder conseguir/ renovar el permiso de residencia (sobre estos últimos véase Van Öers et al. 2010).

23 Sobre la relación entre lengua, construcción identitaria y pertenencia nacional véase Balibar (1998). 
comunidad autonómica con fuertes reivindicaciones soberanistas como Cataluña hubiera decidido traducir al catalán las tres ediciones del Manual, inicialmente disponibles en los (entonces) 23 idiomas oficiales de la UE. Por otra parte es llamativo, ante la creciente difusión del prisma intercultural en la educación, que a la hora de dirigirse a la población migrante no comunitaria el tema del plurilingüismo se reduzca al aprendizaje de la lengua del país receptor, y no por ejemplo a una extensión general de las competencias lingüísticas de toda la población en diferentes idiomas (Martiniello 2007) ${ }^{24}$.

Finalmente, cabe preguntarse si la reducción a técnica de la cuestión lingüística puede terminar favoreciendo las maniobras "ocultas" de algunas voluntades políticas: ante el creciente énfasis en la "dimensión exterior" de la integración, se ha difundido la hipótesis de realizar cursos y test de idioma antes de la salida del país de origen. La idea de que una lengua pueda aprenderse fuera de su contexto socio-cultural de producción es difícilmente sostenible y siembra la duda de que, tal vez, el objetivo principal de ciertas medidas sea el de implementar mecanismos de selección, regulación e "inclusión diferencial" de la fuerza de trabajo migrante en función de determinadas características y niveles de capital social y cultural (Mezzadra y Neilson 2014: 10). Así pues, a través del tema de la lengua se evidencia una tercera acepción del retorno de lo político, en este caso como movimiento que acontece dentro del mismo campo técnico. Dicho con otras palabras, a pesar de la "píldora dorada" de aparente tecnificación, el contenido político no es expulsado, sino más bien subsumido e incorporado en las buenas prácticas, listo para emerger en cualquier momento.

\section{REFLEXIONES CONCLUSIVAS}

Antes de formular observaciones e interrogantes finales, recapitularé las principales argumentaciones avanzadas en el texto. Para empezar, primero he contextualizado histórica y políticamente la emergencia de un marco europeo de políticas "blandas" de integración, ilustrando sus principales hitos. Posteriormente, he analizado el proceso de despolitización y tecnificación al que dichas políticas han sido sometidas, adoptando las buenas prácticas como caso paradigmático. La elección de este ejemplo ha sido justificada por la relevancia que estas han asumido, tanto dentro del proceso de constitución del Marco Europeo de la Integración, como en las "formas de hablar" sobre las políticas de integración en el contexto comunitario. Posteriormente he profundizado en el análisis de su "reducción a técnica", poniendo de relieve que se ha otorgado un sentido muy cientifista a la noción, ahondando en sus límites epistemológicos y reflexionando sobre la inexistencia de una definición de "malas prácticas". Finalmente, he indagado en las distintas formas de "retorno" del elemento político, que se da

${ }^{24}$ Lo cual además contribuiría a descolonizar el imaginario colectivo, poniendo de relieve que muchos migrantes tienen una competencia lingüística más amplia que numerosos ciudadanos europeos. 
en el trasfondo -como estrategia discursiva consciente orientada a contrastar los "populismos" o a implementar más rápidamente las políticas-, al margen -en tanto que lucha entre actores situados por resignificar las prácticas propias como "buenas"- y dentro de lo técnico -resaltando los límites de la operación despolitizadora en casos tan cargados simbólicamente como es el aprendizaje del idioma del país receptor-.

Por otra parte, el caso de las buenas prácticas es representativo de una tendencia existente no solamente en las políticas de integración. Conforme con estudios realizados en otros ámbitos, puede afirmarse que el proceso de (aparente) despolitización y tecnificación aquí descrito refleja una dinámica más amplia y típica de la "racionalidad política neoliberal" (Rose 1999; Brown 2006) que caracteriza las políticas públicas contemporáneas -para dar cuenta de esta contradictoriedad, Bourdieu habla sagazmente de "políticas de despolitización" (2001)-. En particular, dicha tendencia es detectable en aquellos espacios políticos que se implementan mediante marcos de "políticas blandas", "gobernanza multinivel", new public management y otras prácticas de "gobierno reflexivo" (véanse Walters y Haahr 2005; Jaeger 2007; Dean 2010; Davies 2011; Shore 2011; Shore y Wright 2015). Lo que aporta específicamente el estudio de estos procesos, en el contexto de las políticas de integración de inmigrantes, tal vez sea una "tensión" particularmente interesante desde el punto de vista analítico: esto se debe a que las temáticas relevantes para este campo, al remitir a cuestiones como la identidad, la pertenencia o la ciudadanía, se encuentran imbricadas en y atravesadas por importantes mecanismos de inclusión, exclusión e inclusión diferencial. Lo cual proporciona herramientas muy significativas a la hora de detectar los aspectos contradictorios y las ambivalencias latentes.

Finalmente, y para volver a la temática tratada en este artículo, cabe preguntarse en qué medida la acepción "descafeinada" del concepto de buenas prácticas contribuye a ofuscar y a poner en un segundo plano otras preguntas previas, que considero centrales: ¿buenas para qué? ¿Para quién? Y finalmente, ¿quién evalúa y decide sobre su "bondad"? Avanzar estos interrogantes (y tratar de responderlos) equivale a plantear la cuestión de su politicidad. Observa Žižek que "la verdadera lucha política [...] no consiste en una discusión racional entre intereses múltiples, sino que es la lucha paralela por conseguir hacer oír la propia voz y que sea reconocida como la voz de un interlocutor legítimo" (2010: 26-27). Desde este punto de vista, no es baladí observar que en el "vacío tecnocrático" del intercambio de buenas prácticas sobre integración, puede percibirse una gran ausencia: la de las perspectivas y de las subjetividades migrantes, de sus voces y vivencias. En última instancia, es la propia relevancia política de las migraciones (véanse De Lucas 2003; Mezzadra 2005) que parece ser suprimida. Siguiendo a Sayad, podría avanzarse la hipótesis de que esta despolitización está profundamente relacionada con la propia condición "ilegítima" de la persona migrante, la de ser un (o una) "no nacional" cuya presencia es considerada provisional y está justificada únicamente por exigencias económicas: de allí su exclusión del orden político (Sayad 2008: 104). En este sentido, la operacionalización de la integración como una serie de "recetas" y 
"fórmulas" a aplicar esmeradamente acarrea, además de los aspectos observados en las páginas anteriores, la ocultación de su lugar de enunciación: dichas políticas parecen ser formuladas desde la pretensión universal y artificial de un "punto cero" epistemológico (Castro-Gómez 2007), un lugar en el que el sujeto hacedor de las políticas aparece como un "observador desapegado, un buscador de verdades y objetividades neutral, que al mismo tiempo controla las reglas disciplinarias y se sitúa (él o ella) en una posición privilegiada para evaluar y definir" (Mignolo 2010: 14). Un sujeto capaz de observar con mirada de cirujano fenómenos sociales que no solo están profundamente atravesados por desigualdades, sino en los que las fronteras entre lo "objetivo" y lo "subjetivo" se desdibujan muy a menudo. En definitiva, un punto cero ni intermedio ni imparcial, sino desbalanceado hacia el lado de quienes ejercen relaciones de poder más favorables. En conclusión, vale la pena insistir en que el estudio de los discursos sobre la integración tal vez nos diga mucho más acerca de sus autores que sobre la integración misma.

\section{BIBLIOGRAFÍA}

ANDRIJASEVIC, R. y WALTERS, W. (2010): “The International Organization for Migration and the international government of borders", Environment and Planning D: Society and Space, 28, pp. 977-999.

ARRIBAS, A., GARCÍA-GONZÁLEZ, N., SEBASTIANI, L., ÁLVAREZ, A. y GIL, S. (2014): "Revisiting the EU Framework on Immigrant Integration: the European Integration Forum as a Technology of Agency", Ethnicities, 14, pp. 556-576. Disponible en: http://etn.sagepub.com/content/14/4/556.abstract [consulta: 15-102016].

BALBI, F. y BOIVIN, M. (2008): "La perspectiva etnográfica en los estudios sobre política, Estado y gobierno", Cuadernos de Antropología Social, 27, pp. 7-17. Disponible en: http://www.redalyc.org/articulo.oa?id=180913917001 [consulta: 15-10-2016].

BALIBAR, E. (1988): “La forma nación: historia e ideología”, en Raza, Nación y Clase, Madrid, Iepala, pp. 135-168.

BIGO, D. y CARRERA, S. (2007): "From New York to Madrid: Technology as the Ultra-Solution to the Permanent State of Fear and Emergency in the EU", Brussels, Centre for European Policy Studies. Disponible en: http://www.euractiv.com/ section/security/opinion/from-new-york-to-madrid-technology-as-the-ultra-solutionto-the-permanent-state-of-fear-and-emergen/ [consulta: 12-10-2016].

BILDT, C. (2009): Intervención de la Presidencia Sueca de la UE en la segunda reunión del Foro sobre la Integración, Bruselas, Bélgica.

BOURDIEU, P. (2001): “Contra la política de despolitización”, Ecología política, 21, pp. 99-102.

BOURDIEU, P. y WACQUANT, L. (2005): Una invitación a la sociología reflexiva, Madrid, Siglo XXI.

BROWN, W. (2006): Regulating aversion. Tolerance in the Age of Identity and Empire, Princeton, Princeton University Press. 
CARRERA, S. y ATGER, A.F. (2011): Integration as a two-way process in the EU? Assessing the relationship between the European Integration Fund and the Common Basic Principles on Integration, Brussels, Centre for European Policy Studies (CEPS).

Disponible en: https://www.ceps.eu/system/files/book/2011/07/Integration\%20as\%20 a\%20Two-way\%20Process.pdf [consulta: 15-10-2016].

CASTEL, R. (1997): Las metamorfosis de la cuestión social. Una crónica del asalariado, Barcelona, Paidós.

CASTRO-GÓMEZ, S. (2007): “The Missing Chapter of Empire. Postmodern reorganization of coloniality and post-Fordist capitalism", Cultural Studies, 21(2-3). Disponible en: http://www.tandfonline.com/doi/pdf/10.1080/09502380601162639? redirect=1\#.VoJzYPnhDIU [consulta: 15-10-2016].

COM(2011) 455 final: Comunicación de la Comisión al Consejo, al Parlamento Europeo, al Comité Económico y Social Europeo y al Comité de las Regiones. Agenda Europea para la Integración de los Nacionales de Terceros Países.

Disponible en: http://ec.europa.eu/transparency/regdoc/rep/1/2011/ES/1-2011-455ES-F1-1.Pdf [consulta: 15-10-2016].

COMISIÓN EUROPEA (2004): Manual sobre la integración para responsables de la formulación de políticas y profesionales, Bruselas, Comunidades Europeas.

Disponible en: https://ec.europa.eu/migrant-integration/index.cfm?action=furl.go\&go=/ librarydoc/handbook-on-integration-for-policy-makers-and-practitioners-1stedition---2004 [consulta: 15-10-2016].

COMISIÓN EUROPEA (2007): Manual sobre la integración para responsables de la formulación de políticas y profesionales. Segunda edición, Bruselas, Comunidades Europeas. Disponible en: https://ec.europa.eu/migrant-integration/index. $\mathrm{cfm}$ ?action=furl.go\&go=/librarydoc/handbook-on-integration-for-policy-makersand-practitioners-2nd-edition [consulta: 15-10-2016].

COMISIÓN EUROPEA (2010): Manual sobre la integración para responsables de la formulación de políticas y profesionales. Tercera edición, Bruselas, Unión Europea. Disponible en: https://ec.europa.eu/migrant-integration/index.cfm?action=furl. go\&go=/librarydoc/handbook-on-integration-for-policy-makers-and-practitioners3rd-edition---2010 [consulta: 15-10-2016].

CONSEJO DE LA UNIÓN EUROPEA (2004): Sesión número 2618 del Consejo de Justicia y Asuntos de Interior. Bruselas, 19 de noviembre de 2004, 14615/04. Disponible en: http://europa.eu/rapid/press-release PRES-04-321 es.htm [consulta: 15-10-2016].

CONSEJO EUROPEO (1999): Consejo Europeo de Tampere, 15 y 16 de octubre de 1999. Conclusiones de la Presidencia. Disponible en: http://www.europarl.europa. eu/summits/tam es.htm [consulta: 15-10-2016].

DAVIES, J. (2011): "Repensando las redes: gobernanza como hegemonía", en Gobernanza. Teoría y prácticas colectivas, Barcelona, Anthropos, pp. 37-65.

DEAN, M. (2010): Governmentality. Power and Rule in a Modern Society, London, Sage.

DE GENOVA, N. (2016): "The 'crisis' of the European border regime: Towards a Marxist theory of borders", International Socialism, 150. Disponible en: http:// isj.org.uk/the-crisis-of-the-european-border-regime-towards-a-marxist-theory-ofborders/ [consulta: 12-10-2016]. 
DE LUCAS, J. (2003): "La inmigración, como res política", en Movimientos de personas e ideas y multiculturalidad (vol. II), Bilbao, Universidad de Deusto, pp. 193-225.

FAVELL, A. (2001a): “Multicultural nation-building: 'integration' as a public philosophy and

research paradigm in Western Europe", Swiss Political Science Review, 7(22), pp. 116124.

FAVELL, A., (2001b): “Integration Policy and Integration Research in Europe: A Review and

Critique", en Citizenship Today. Global Perspective and Practices, Washington, Carnegie Endowment for International Peace, pp. 349-399.

FOUCAULT, M. (2009): Las palabras y las cosas: una arqueología de las ciencias humanas, Madrid, Siglo XXI.

GIL, S. (2006). Las argucias de la integración. Tesis doctoral, Madrid, Universidad Complutense

de Madrid. Disponible en: http://www.flacsoandes.edu.ec/web/imagesFTP/6670.tesis sandra.pdf [consulta: 15-10-2016].

GIL, S. (2011) "Las argucias del concepto de integración. Una exploración por el paisaje europeo", Oñati Socio-Legal Series, 1(3), pp. 349-399. Disponible en:

http://papers.ssrn.com/sol3/papers.cfm?abstract id=1831111 [consulta: 15-10-2016].

GRAMSCI, A. (2012): Quaderni dal carcere. Vol. 5: Il Risorgimento, Roma, EIR.

GUIRAUDON, V. (2003): "The Constitution of a European Immigration Policy Domain: a Political Sociology Approach”, Journal of European Public Policy, 10(2), pp. 263-282. Disponible en:

http://www.tandfonline.com/doi/abs/10.1080/1350176032000059035\#.VoJ1kfnhDIU [consulta: 15-10-2016].

HAMMERSLEY, M. (2013): The myth of research-based policy \& practice, London, Sage.

HARAWAY, D. (1988): "Situated Knowledges: the Science Question in Feminism and the Privilege

of Partial Perspective", Feminist Studies, 14(3), pp. 575-599.

JAEGER, J. (2007): “"Global Civil Society' and the Political Depoliticization of Global Governance", International Political Sociology, 1(3), pp. 257-277.

JOPPKE, C. y MORAWSKA, E. (2003): "Integrating Immigrants in Liberal NationStates: Policies and Practices", en Toward Assimilation and Citizenship: Immigrants in Liberal Nation-States, Hampshire, Macmillan, pp. 1-36.

MARTINIELLO, M. (2007). Towards a coherent approach to immigrant integration policy(ies) in the European Union. Joint EC/OECD Project "Gaining from Migration”. Disponible en: http://orbi.ulg.ac.be/handle/2268/143718 [consulta: 1510-2016].

MEZZADRA, S. (2005): Derecho de fuga. Migraciones, ciudadanía y globalización, Madrid, Traficantes de Sueños.

MEZZADRA, S. y NEILSON, B. (2014): Confini e frontiere. La moltiplicazione del lavoro nel mondo globale, Bologna, Il Mulino.

MIGNOLO, W. (2010): "Desobediencia Epistémica (II), Pensamiento Independiente y Libertad

De-Colonial", Otros Logos Revista de Estudios Críticos, 1(1), pp. 8-42. Disponible en: http://www.ceapedi.com.ar/otroslogos/revistas/0001/mignolo.pdf [consulta: 15-102016]. 
MIGRATION POLICY GROUP (2010): From principles to practice. The Common Basic Principles on integration and the Handbook Conclusions - updates, Bruselas, Migration Policy Group. Disponible en:

http://www.migpolgroup.com/archive/public/docs/174.Updated_From principlestopractice theCBPsonIntegration\&HandbookConcls.pdf [consulta: 1510-2016].

MITSILEGAS, V. (2012): "Immigration Control in an Era of Globalization. Deflecting Foreigners, Weakening Citizens, Strengthening the State", Indiana Journal of Global Legal Studies, 19(1), pp. 3-60.

MOUFFE, C. (2007): En torno a lo político, Buenos Aires, Fondo de Cultura Económica.

RANCIÈRE, J. (1996): El desacuerdo. Política y filosofía, Buenos Aires, Ediciones Nueva Visión.

ROSE, N. (1999): Powers of Freedom. Reframing Political Thought, Cambridge, Cambridge University Press.

SANTAMARÍA, E., (2002): La incógnita del extraño. Una aproximación a la significación sociológica de la inmigración no comunitaria, Barcelona, Anthropos.

SAYAD, A. (2002): La doppia assenza. Dalle illusioni dell'emigrato alle sofferenze dell'immigrato, Milano, Cortina Editore.

SAYAD, A. (2008): "Estado, nación e inmigración. El orden nacional ante el desafío de la inmigración”, Apuntes de investigación del Cecyp, 13, pp. 101-116.

SEBASTIANI, L. (2014): "El Marco Europeo de la Integración y la sociedad civil organizada: prácticas participativas, patrones de agencia y producción de saberes", Papeles del Ceic, 1, pp. 1-37.

SEBASTIANI, L. (2015): "Desenredando las políticas públicas de la Unión Europea. El conjunto

Principios Básicos Comunes/Fondo Europeo para la Integración como una tecnología de gobierno", Política y Sociedad, 52(1), pp. 205-232.

SHORE, C. (2010): "La antropología y el estudio de la política pública: reflexiones sobre la 'formulación' de las políticas", Antípoda, 10, pp. 21-49.

Disponible en: http://antipoda.uniandes.edu.co/view.php/147/index.php?id=147 [consulta: 15-10-2016].

SHORE, C. (2011): “European Governance' or Governmentality? The European Commission and the Future of Democratic Government", European Law Journal, 17(3), pp. 287-303.

SHORE, C. y WRIGHT, S. (1997): "Policy: A new field of anthropology", en Anthropology of Policy. Critical perspectives on Governance and power, London, Routledge, pp. 3-39.

SHORE, C. y WRIGHT, S. (2011): "Conceptualising Policy: Technologies of Governance and the Politics of Visibility", en Policy worlds. Anthropology and the Analysis of Contemporary Power, New York-Oxford, Berghahn Books, pp. 1-25.

SHORE, C. y WRIGHT, S. (2015): "Governing by numbers: audit culture, rankings and the new world order", Social Anthropology, 23(1), pp. 22-28.

VAN ÖERS, R., ERSBOLL, E., y KOSTAKOPOULOU, D. (2010): A Redefinition of Belonging? Language and Integration Tests in Europe, Leiden, Martinus Nijhoff.

WACQUANT, L. (2009): "Extirpar y expulsar: sobre la gestión penal de los inmigrantes postcoloniales en la Unión Europea”, Anales de la Cátedra Francisco Suárez, 43, pp. 141-149. 
WALTERS, W. y HAAHR, J. (2005): Governing Europe. Discourse, governmentality and European integration, London-New York, Routldege.

ŽIŽEK, S. (2003): Ideología: un mapa de la cuestión, Madrid, Fondo de cultura económica de España.

ŽIŽEK, S. (2010): En defensa de la intolerancia, Madrid, Biblioteca de Pensamiento Crítico 